\title{
Congenital chloride diarrhea: late presentation
}

This article was published in the following Dove Press journal:

Pediatric Health, Medicine and Therapeutics

I April 201 I

Number of times this article has been viewed

\author{
Laila Al Bishi' \\ Mustafa Al Toonisi² \\ Pediatric Department, North West \\ Armed Forces Hospital, Tabuk, \\ Kingdom of Saudi Arabia
}

\begin{abstract}
We report the case of a male infant who presented with diarrhea at 6 months of age. He was failing to thrive, and biochemical investigation revealed hypokalemic hypochloremic metabolic alkalosis. Diagnosis of congenital chloride diarrhea was suspected and confirmed by the stool chloride result. He was started on high-dose sodium chloride and potassium chloride to control the electrolyte imbalance. The disease was difficult to control for a year after diagnosis. Late presentation is associated with severe chronic electrolyte disturbances and high-dose replacement therapy.
\end{abstract}

Keywords: congenital chloride diarrhea, hypokalemic hypochloremic metabolic alkalosis, high stool chloride

\section{Introduction}

Congenital chloride diarrhea (CCD) is a recognized rare autosomal recessive disorder of intestinal chloride absorption, presenting clinically with watery diarrhea (high stool chloride content), electrolyte disturbances, and metabolic alkalosis. It is caused by mutations in the chromosome 7 gene. The disease occurs in all parts of the world but is more common in some populations with genetic founder effects (eg, Poland, the Persian Gulf, and Saudi Arabia). Highest frequencies (up to 1 in 3200) have been reported among Arabs, where parental consanguinity is common. A G187X mutation is responsible for more than $90 \%$ of these cases. ${ }^{1}$

\section{Case presentation}

A 6-month-old infant presented to an emergency room with a history of diarrhea for 2 weeks and fever and vomiting for 3 days. The patient was born via spontaneous vaginal delivery, at term, to a first cousin young Saudi couple who had another older healthy child with no deaths in the family. The mother had an irregular and poor antenatal follow-up. A scan at 35 weeks of gestation revealed polyhydromnious with dilated fetal intestinal loops suggestive of fetal intestinal obstruction. The baby was admitted to the neonatal intensive care unit for further evaluation. He was not dysmorphic, he was pink, his birth weight was $2.0 \mathrm{~kg}$ (1.5 standard deviations [SD] below mean for his age), and his length and head circumference were $45 \mathrm{~cm}$ and $32 \mathrm{~cm}$, respectively (both of which lie on the 5th percentile). A postnatal pediatric surgery evaluation along with a roentgenographic series and abdominal ultrasound ruled out intestinal obstruction. He passed meconium on the first day of life followed by an otherwise grossly normal stool character and frequency (four to five times)/day. At 2 days of age, he was cultured and treated for sepsis as well as single phototherapy for mild indirect 
hyperbilirubinemia. His electrolytes were normal, including bicarbonate level. He was discharged home after negative cultures. Postdischarge, he had occasional self-resolving 1-2 days of profuse watery stool two to three times per day every 2 weeks. He was exclusively breastfed.

At 6 months of age, he presented with a 2-week history of profuse watery diarrhea, occurring five to six times a day, associated with on and off nonbilious vomits. He was initially managed as an outpatient (family medicine clinic) with oral rehydration solution. As his condition deteriorated, he was thereafter brought to the emergency room with fever and the aforementioned complaints. There was no history of abdominal distention, decreased activity, or abnormal movements. Clinical assessment revealed an irritable, moderately dehydrated infant.

Anthropometric measures were weight $5.3 \mathrm{~kg}$ (2 SD below mean for age) and length and head circumference $62 \mathrm{~cm}$ and $40 \mathrm{~cm}$, respectively (1 SD below mean for age) (Figure 1). His blood pressure was normal for his age and his abdomen was moderately distended, soft, and lax, with neither organomegaly nor masses. Bowel sounds were audible. Both renal angles were free with intact hernial orifices and normal male genitalia.

The laboratory investigations are shown in Tables 1 and 2.

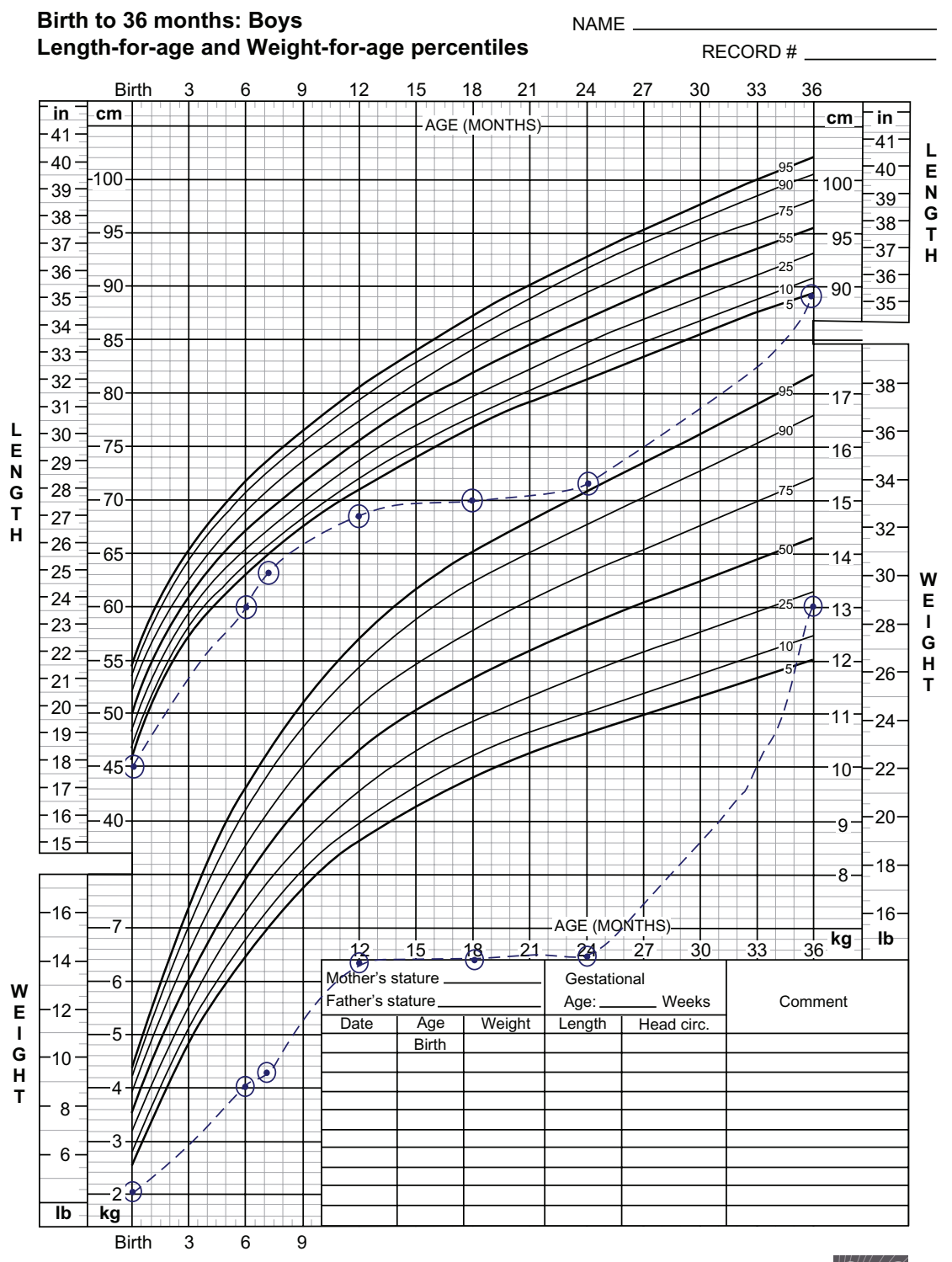

QDC

SAFER $\cdot$ HEALTHIER PEOPLE

Figure I Patient growth chart. Reproduced with permission from National Center for Chronic Disease Prevention and Health Promotion (c) 2000. ${ }^{2}$ 
Table I Results for serum electrolytes

\begin{tabular}{|c|c|c|c|c|c|c|c|c|c|}
\hline & \multicolumn{9}{|c|}{ Blood chemistry } \\
\hline & Sodium & Chloride & Potassium & Bicarbonat & Glucose & Calcium & Magnesium & Urea & Creatinine \\
\hline Normal & $133-46$ & $98-107$ & $3.5-5.1$ & $16-24$ & $3.3-5.6$ & $2.0-2.5$ & $0.65-1.0$ & $1.8-6.4$ & $18-35$ \\
\hline values & $\mathrm{mmol} / \mathrm{L}$ & $\mathrm{mmol} / \mathrm{L}$ & $\mathrm{mmol} / \mathrm{L}$ & $\mathrm{mmol} / \mathrm{L}$ & $\mathrm{mmol} / \mathrm{L}$ & $\mathrm{mmol} / \mathrm{L}$ & $\mathrm{mmol} / \mathrm{L}$ & $\mathrm{mmol} / \mathrm{L}$ & $\mu \mathrm{mol} / \mathrm{L}$ \\
\hline Day I & 124 & 70 & 1.8 & 48 & 5.8 & 2.29 & 0.80 & 6 & 44 \\
\hline Day 2 & $|3|$ & 81 & 2.3 & 44 & 5.2 & 2.37 & 0.79 & 3.4 & 35 \\
\hline Day 3 & 129 & 77 & 3.5 & 40 & 4.3 & 2.4 & 1.0 & 4.7 & 40 \\
\hline Day 5 & 136 & 94 & 4.7 & 32 & 4.6 & 2.47 & - & 5 & 24 \\
\hline
\end{tabular}

\section{Management}

In the emergency room, a normal resuscitation saline fluid of $20 \mathrm{~mL} / \mathrm{kg}$ was delivered over 30 minutes. The patient was then admitted to the pediatric ward and treated for gastroenteritis. Intravenous fluid was calculated as maintenance and $10 \%$ deficit over 24 hours. Boluses of intravenous potassium chloride as well as $3 \%$ hypertonic saline were given for his hypokalemia and hyponatremia, respectively, which showed gradual improvement, as shown in Table 1. The differential diagnoses of hypokalemic hypochloremic metabolic alkalosis were Bartter's syndrome and pseudo-Bartter's syndrome.

The Pseudo-Bartter's syndrome diagnosis was made because the patient had no urine electrolyte loss. Furthermore, his perinatal history was suggestive of CCD and he was witnessed by the attended medical team to pass a gush of soup-like stool. Finally, the stool chloride result confirmed the diagnosis of CCD (Table 2). Genetic testing was not carried out, as it was unavailable in the center.

The baby required a high dose of sodium chloride and potassium chloride up to $9-10 \mathrm{mmol} / \mathrm{kg} /$ day to normalize his potassium, chloride, and sodium levels. He was referred to a dietitian to be given a high-calorie formula. The patient was then discharged on oral salt medication.

The infant afterwards had multiple admissions due to breakthrough illness and electrolyte imbalances that affected his weight gain. However, the developmental milestones were appropriate for his age. A follow-up at 3 years of age showed good catch-up growth, as shown in Figure 1. However, he had speech delay, unilateral conversion sequent, and hyperactivity behavior.
The boy was referred to ophthalmology; ear, nose, and throat; and pediatric neurology subspecialties for evaluation. A baseline computed tomography scan of the brain was unremarkable.

\section{Discussion}

It was apparent retrospectively that the patient had mild chronic diarrhea despite the fact that it was not stated clearly by parents, as it was episodic and self-resolving.

The differential diagnosis of failure to thrive and the electrolyte disturbances were Bartter's syndrome and pseudoBartter's syndrome. The latter is often difficult to distinguish from Bartter's syndrome. In addition to hypokalemia, hypochloremic metabolic alkalosis is characterized by normal blood pressure with an increased urinary loss of sodium, chloride, potassium, and calcium. Gitelman's syndrome is considered to be one phenotype of Bartter's syndrome and is characterized by hypomagnesemia, hypocalciuria, and hypertension; however, the presentation commonly does not occur during the infancy period. ${ }^{3}$ Therefore, Bartter's syndromes (Bartter's and Gitelman's syndromes) were less likely in our patient. On the other hand, pseudo-Bartter's syndrome can be a presentation of chronic diseases like cystic fibrosis or CCD.

Although the classical presentation of CCD began antenatally, was diagnosed shortly after birth, and could have been lethal if not treated, this case was unusually presented during infancy. That indicates that survivors with untreated CCD seem to develop a less severe, chronic course of the disease, the identification of which may be

Table 2 Results for urine and stool electrolytes

\begin{tabular}{|c|c|c|c|c|c|c|c|c|}
\hline & \multicolumn{4}{|c|}{ Random urine electrolytes } & \multicolumn{4}{|c|}{ Random stool electrolytes } \\
\hline & Sodium & Chloride & Potassium & $\begin{array}{l}\text { Calcium/ } \\
\text { creatinine ratio }\end{array}$ & Magnesium & Sodium & Chloride & Potassium \\
\hline Normal value & I5-20 meq/L & $15-20 \mathrm{meq} / \mathrm{L}$ & I5-20 meq/L & $<0.6$ & $0.6-0.9 \mathrm{mmol} / \mathrm{L}$ & $50-60 \mathrm{mmol} / \mathrm{L}$ & $6-17 \mathrm{meq} / \mathrm{L}$ & \\
\hline Results & 21 & 18 & 10 & 0.1 & 0.9 & 85 & 118 & NA \\
\hline
\end{tabular}

Abbreviation: NA, not available. 
highly challenging. ${ }^{4}$ Persistent diarrhea is, however, often associated with particular vulnerability to dehydration and severe hypoelectrolytemia during the episodes of gastroenteritis and also during other common childhood infections. ${ }^{5}$ Growth retardation is one of the extraintestinal manifestations of late diagnosis; ${ }^{6}$ however, many other factors could contribute to stunted growth in this patient, eg, recurrent readmission, which interferes with appetite and wellbeing; an improper weaning program; and compliance.

\section{Conclusion}

We conclude that CCD can be diagnosed during the late infancy period and even at an older age. One of the clinical presentations is a mild chronic course; however, hypovolemia and hypoelectrolytemia can be severe during intercurrent illness. The later the diagnosis, the higher the dose of salt replacement therapy is needed. Weight gain may be difficult after diagnosis; therefore, optimal therapy, a high-calorie diet, and regular clinic follow-up might help to improve growth retardation.

Screening of fecal chloride concentration should be performed in all patients, especially neonates with a family history of CCD or antenatal findings suggestive of the disease, eg, polyhydramnios and/or intestinal dilated loops.

\section{Acknowledgment}

Great thanks go to the pediatric clinic's pediatric secretary Junelyn Mondala and charge nurse Ruth Gonzales for facilitating data collection and manuscript writing.

\section{Disclosure}

The authors report no conflicts of interest in this work.

\section{References}

1. Höglund P, Auranen M, Socha J, et al. Genetic background of congenital chloride diarrhea in high-incidence populations: Finland, Poland, and Saudi Arabia and Kuwait. Am J Hum Genet. 1998;63:760-768.

2 Centers for Disease Control and Prevention. Growth Charts [updated 2010 Sep 9]. Available at http://www.cdc.gov/growthcharts. Accessed March 28, 2011.

3. Amirlak I, Dawson KP. Bartter syndrome: an overview. $Q J$ Med. 2000; 93:207-215.

4. Holmberg C. Congenital chloride diarrhoea. Clin Gastroenterol. 1986; 15:583-602.

5. Holmberg C, Perheentupa J, Launiala K, Hallman N. Congenital chloride diarrhoea. Clinical analysis of 21 Finnish patients. Arch Dis Child. 1977; 52:255-267.

6. Höglund P, Holmberg C, Sherman P, Kere J. Distinct outcomes of chloride diarrhea in two siblings with identical genetic background of the disease: implications for early diagnosis and treatment. Gut. 2001; 48:724-727.
Pediatric Health, Medicine and Therapeutics

\section{Publish your work in this journal}

Pediatric Health, Medicine and Therapeutics international, peerreviewed, open access journal publishing original research, reports, editorials, reviews and commentaries. All aspects of health maintenance, preventative measures and disease treatment interventions are addressed within the journal. Practitioners from all disciplines are invited to submit

\section{Dovepress}

their work as well as healthcare researchers and patient support groups. The manuscript management system is completely online and includes a very quick and fair peer-review system. Visit http://www.dovepress. com/testimonials.php to read real quotes from published authors. 